\title{
Correction to: Post-Truth and Political Discourse
}

\section{Correction to:}

D. Block, Post-Truth and Political Discourse, https://doi.org/10.1007/978-3-030-00497-2

The original version of the book has been revised with the following corrections:

In Chapter 1, Pages 7 and 15, author name in the citations "Anderson 2017" and "Anderson, P. (2017)" should read "Andrews".

In Chapter 3, Page 73, the text "which he finally was able to repeal with much fanfare in May 2017" should read "which he announced that he would repeal with much fanfare in May 2017".

The final corrections have been incorporated.

The updated version of these chapters can be found at https://doi.org/10.1007/978-3-030-00497-2_1 https://doi.org/10.1007/978-3-030-00497-2_3

(C) The Author(s) 2019

D. Block, Post-Truth and Political Discourse, https://doi.org/10.1007/978-3-030-00497-2_5 